Bert Olivier

\title{
Postmodern cinema and postmodern culture: information-communication, otherness and history in Wenders's Himmel über Berlin (Wings of Desire)
}

\begin{abstract}
What one may call the obscenity of infonmation is the conmon thread that nus through Wim Wenders's film Wings of Desire, postmodem culture and Baudrillard's radical cultural critique. The latter shows that communication has degenerated into the availability of information (in advanced, post-industrial countries, at least), while Wenders's film provides a paradigm for the problematization of communication and personal history in a postmodem culture of fragmentation.
\end{abstract}

\section{Introduction}

What do angelic sentiency (à la Wenders), Baudrillard's cultural critique and postmodern culture have in common? In a word: the obscenity of information. Wim Wenders's hauntingly beautiful film, Himmel über Berlin (English title: Wings of Desire) is a narrative juxtaposition, and an eventual exchange of angelic and human modes of perception. It is also a simultaneous problematization and celebration of the possibility of human temporality as personal history and of communication in a cultural context characterized by fragmentation and what Lyotard calls "the temporary contract" (Harvey, 1990:113).

This rather condensed description of the film clearly requires considerable elaboration, including a reconstruction of its narrative, however brief. Let me therefore begin with an apt evocation of "the condition of postmodernity" (which also happens to be the title of its source) by David Harvey.

\subsection{Cultural fragmentation}

Spaces of very different worlds seem to collapse upon each other, much as the world's commodities are assembled in the supermarket and all manner of subcultures get juxlaposed in the contemporary city. Disruptive spatiality triumphs over the coherence of perspective and narrative in postmodern fiction, in exactly the same way that imported beers coexist with local brews, local employment collapses under the weight of foreign competition, and all the divergent spaces of the world are assembled nightly as a collage of images upon the television screen (Harvcy, 1990:301-302). 
Harvey's verbal collage not only signifies the structure of postmodern culture, but at once touches upon important aspects of postmoderm film - particularly Wings of Desire, as well as others such as Woody Allen's Zelig and Ridley Scott's Blade Runner, which will be referred to again. All three of these films articulate the sense of fragmentation - cultural and personal - that Harvey captures so well in the earlier quotation, and problematize the connections between time, space, history, self and others in different ways. Although the thematization in this article will focus on and develop very specific aspects of Wings of Desire, Harvey's perceptive discussion of the film is utilized in many respects.

\section{From eternity to time in Wings of Desire}

In Wings of Desire this cultural fragmentation is presented to us in the first place from the spatio-temporally unbounded vantage point(s) of two angels. Unfettered by human perspectivism, they have full audiovisual access to humans and their private thoughts. These individuals come across as isolated, and their thoughts as unrelated and ephemeral, and are recorded in monochrome and monotone. (Cf. Blue Thunder as fictional technological approximation of angelic vision and hearing.) The overwhelming impression created by the angelic perception of labyrinthine living spaces and their inhabitants, is one of isolation, division, alienation and non-communication. This is underscored by the fact that the film-narrative is set in Berlin, where The Wall was until not so long ago a kind of archetype of the dividedness of the human race. The sequence of audiovisual images makes it clear, however, that Berlin is not unique in this respect, but simply representative of all the world's cities interconnected by global information- and transportation-networks, the implication being that, the advanced international information- and communicationnetworks notwithstanding, divisions remain intact everywhere.

\subsection{Transcending the angelic dimension of eternity}

Simplifying to the extreme, and ignoring sub-themes for the time being, one could say that Wings of Desire enacts the story of an angel, Damiel. Damiel is increasingly dissatisfied and frustrated at his inability to transcend the angelic dimension of eternity, in order to interact with humans, in time and in bounded space. He shares his desire to experience the 'heaviness' of human existence with a fellow angel - a desire, which incidentally, makes the English title of the film very appropriate. To use a familiar distinction from a novel by Milan Kundera - albeit here generating different connotations in a different context Damiel is increasingly burdened by the 'unbearable lightness of being', and drawn to the 'heaviness' of human becoming.

Although the causal link is not established explicitly in the film, this could at least partly be because the angels' attempts to influence human affairs are not guaranteed to succeed. The audience witnesses some successes on their part, but also failures - the young man, for example, commits suicide over his lost love despite the angels' attempts to prevent it. These attempts do not take the form of actual, volitional interventions in the course of human action, however: being outside human time, the angels can at best try to offer spiritual comfort by their presence. They cannot influence human decisions directly, or, as one of them points out ruefully, they cannot really take part in humans' lives - they can merely pretend to do so. The angel Damiel, already drawn to the 'here and now' of human existence, develops an interest in a beautiful trapeze artist, Marion. Although Harvey does 
not comment on the implications of her being a trapeze artist, it is significant. Of all 'heavy' humans, the trapeze artist, who defies the laws of gravity, not only thus approximates the 'lightness' of the angels, but exemplifies the precariousness and contingency of human spatio-temporality - which is precisely what attracts Damiel.

Here, already, is a potential point of encounter between Damiel and a human, in the midst of a postmodern landscape of fragmentation and interpersonal isolation. Add to this that Marion's act is located within the enclosed space of the circus tent (something that Harvey, [1990:318] does consider), which constitutes one of the spaces in the film (the other one being the library) where a fragile sense of human identity exists and interaction can take place, and the stage is set for Damiel's momentous decision. After all, a tent has long been associated with a nomadic existence, signifying brief, intermittent sojourns in the course of a life of travelling (or of life as a journey, perhaps even a quest). And the circus is the place that signifies the (pre-electronic media) spectacle where human daring and hard-won skills challenge human 'heaviness' and fallibility continually. As every circus artiste knows anyone could fall, any time. It makes perfect sense that this environment, and this woman Marion in it, attract Damiel so powerfully. His decision to exchange angelic eternity for human history entails his falling into the temporal realm of mortality - an interesting inversion of the fall of Lucifer, whose fall, it must be remembered, was the result of his project of pride. Damiel's fall, in contrast, is not prompted by the (angelic) hubris of aspiring to divinity, but corresponds instead with the original lapse, to the extent that it renders him truly human. Insofar as the film-narrative emphasizes the contingency, alienation, precariousness, mortality, fragility and vulnerability of the human condition, together with the fact that this is precisely what the angel Damiel finds so powerfully attractive about it, Wenders's film is an anti-Platonic celebration of radical finitude and contingency.

\subsection{The narrative problematizing of interpersonal communication and personal history}

What has been stated about the film-narrative should not be construed to mean that the 'human condition' is presented in a free-floating, apparently culture-independent manner. The isolation and alienation of the people who inhabit its diegetic space are clearly shown to be the anthropological constituents of a postmodern media-, information- and diversified capital-saturated culture - which provides the necessary context for Wenders's narrative problematization of interpersonal communication and personal history. In short, the film explores the question: are communication and personal history (i.e. a sense of continuity and identity) possible in a culture such as this? This question is all the more important, given the conviction on the part of someone like Fredric Jameson (Nicholls, 1991:1-2) that postmodernism is a predominantly spatial phenomenon, with the problematics of time and history - so characteristic of modernism - all but eclipsed in a postmodern culture. Peter Nicholls (1991), for one, challenges Jameson's contention, citing Lyotard and various instances of recent writing to show that a sense of the problematics of temporality may indeed be located in the postmodern. Similarly, in so far as Wings of Desire takes up the theme of eternity (with its limitless perception) and temporality (with its challenging limitations), Wenders also appears to contest Jameson's contention that the thematics of spatiality constitute the major distinction between the modern and the postmodern.

Damiel's eventual decision, in Wings of Desire, to enter human history, happens in the stretch of no-man's land between the two lines of the Berlin Wall, the potential 
disastrousness of which (emphasizing his newly acquired human vulnerability) is averted by his fellow angel who places him on the western side of the Wall. Harvey (1990:318-319) observes that Damiel's decision is triggered by two "catalytic moments" - which, incidentally, may also be read as transitional with regard to his impending change of status, given the fact that both events involve a certain closeness (itself a communicational motif) to human beings. In the first of these, Damiel sees himself in Marion's dream of the dazzlingly bright 'other' and follows her into a nightclub where she feels and responds to his presence while she is dancing by herself. The second event involves Peter (Columbo) Falk, playing an international media star (himself!) who happens to be an ex-angel that took the plunge some time before, and who, sensing the invisible Damiel's presence where he is drinking coffee at a stall, addresses the surprised angel, telling him how good it is to live in human time and experience the sensory variety of human materiality.

When Damiel wakes up as a human, he perceives colours for the first time, including the redness of his own blood (from a newly-made-possible wound sustained in his fall), which he identifies linguistically by interrogating a nonplussed passer-by. This is a significant event in terms of the theme of this article, because it differentiates between unidimensional information (the monochromatic omni-vision of the angels) and communication, which always presupposes an element of otherness that simultaneously necessitates and vindicates the communication between two or more persons. Equally significant is the fact that Damiel has to appropriate finite human spatiality by traversing the city on foot, in the course of which a certain sense of coherence emerges, replacing the overwhelming impression of fragmentation that issues from the (fictional) angelic omni-vision, however paradoxical that may seem. Harvey captures the difference between these two, the finite and the suprafinite, where he comments (Harvey, 1990:319):

This human sense of space and motion contrasts with that of angels, earlier depicted as a hyper-space of speeding flashes, each image like a cubist painting, suggesting a totally different mode of spatial experience. Damiel shifts from one mode to the other as he enters the flow of time.

The economic power of money in the human world is emphasized by the fact that, having become human, Damiel needs money to survive. The fact that money, like advanced information-systems, surpasses national barriers, thus homogenizing global economic space, is brought home by the scene on the set where Peter Falk is filming. The latter, realizing who Damiel is when he shouts to the media star through a fence which separates them, overcomes the constructed barrier by talking to the newly human ex-angel through the fence and kindly giving him some money. "Damiel's entry into this human world", says Harvey (1990:319), "is now firmly located within the co-ordinates of social space, social time, and the social power of money".

\section{The attempt to create a fake present history}

The eventual meeting between Marion and Damiel happens at the same nightclub where she felt his presence before. After tentatively eyeing each other for a while they come face to face in an adjacent bar. Earlier, after the circus had closed down for lack of money (Lyotard's short-term contract), Marion had been resolute about making a story for herself, even without the circus. (Harvey [1990:318] draws attention to the function of the photo image in this context, where Marion imagines using a photo-automat to create a new identity, something which is symptomatic of an era or society where the sense of continuity imparted by a coherent tradition is absent. In Blade Runner the replicants resort to 
photographs as well, to construct or fake the personal history which they lack). Now, in Damiel's presence (in the bar), she prepares to enact her (hi-)story with him - to "supersede being with becoming", in Harvey's words (1990:319). Damiel, too, is ready to experience his new-found, mundane spatio-temporality to the full. What follows articulates an imagined antithesis to the fragmentation and discontinuity of advanced capitalist (postmodern) society. Marion makes it clear that she has a common project in mind for the two of them - a project that would overcome arbitrariness and temporariness, and would somehow forge something universal out of the particular (a problem that postmodern art and architecture have always struggled with, in their attempt to mediate between difference and the universalistic demands of modernism). From the lengthy discourse a new sense of wholeness and identity emerges, linked to an ideal for all of mankind - a renewed project of creating a story of unity-in-difference through a shared decision. The narrative ends with Damiel helping Marion with her trapeze act after their first night together: the angel-become-human reassuringly keeping a watchful eye lest this lightest of heavy humans should slip and fall - a striking image of interhuman support. The final shots also include footage of an old man, the storyteller, whose importance will also be touched upon.

It is true that, as Harvey observes $(1990: 320,322)$ the film's ending tends to become somewhat banal and suffused with romanticism as a possible source of dealing with the distressing conditions of an alienating culture. The fact that Marion and Damiel are prepared to learn from each other, however, constitutes a communicational paradigm, and explains Harvey's remark, that he interprets the part of the film that deals with their relationship "... as an attempt to resurrect something of the modernist spirit of human communication, togetherness, and becoming, out of the ashes of a monochromatic and dead-pan postmodernist landscape of feeling".

\section{Postmodernity, hyperreality and the obscenity of information}

To be able to appreciate what is at stake here, a detour is necessary through this postmodern landscape. The principal guide on this occasion will be Jean Baudrillard, whose radical critique of contemporary postindustrial culture provides an interpretive grid for cultural artifacts like Wings of Desire. It is important to remember here that despite the differences between a modernist and a postmodernist aesthetic - the fact that the former counters conditions of fragmentation, flux and ephemerality in modern society by insisting on (inter alia) unity, functionality, and rational planning, while the latter tends to revel in these differences, fragmentation and 'opaque otherness' - there is a strong continuity between them. Postmodernism may be regarded as a kind of crisis within modernism, one which manifests itself as scepticism concerning questions of universality, immutability, metatheory, and so on (Harvey, 1990:116). But the point is that both - modernism and postmodernism - are responses, in varying aesthetic and critical modes, to the sociocultural effects of modernization. These effects, some of which have already been mentioned, are related to what Harvey (1990:147, 240-307) calls "time-space compression" - a concept the coining of which must be placed in the context of Berman's contention, that modernity is "a certain mode of experience of space and time" (cf. Harvey, 1990:201). Needless to say, the modernism/postmodernism debate is located, to a considerable degree, within the parameters established by this insight, and involves a host of thinkers that include Daniel Bell, Fredric Jameson, Jürgen Habermas, Jean-Francois Lyotard and Jean Baudrillard, to mention but a few. "Time-space compression", which Harvey 
associates primarily with the capitalist world, implies that, as illustrated by the following quotation (Harvey, 1990:147):

... the time horizons of both private and public decision-making have shrunk, while satellite communication and declining transport costs have made it increasingly possible to spread those decisions immediately over an ever wider and variegated space.

I mean to signal by that term processes that so revolutionize the objective qualitities of space and time that we are forced to alter, sometimes in quite radical ways, how we represent the world to ourselves. I use the word 'compression' because a strong case can be made that the history of capitalism has been characterized by speed-up in the pace of life, while so overcoming spatial barriers that the world sometimes seems to collapse inwards upon us. ... As space appears to shrink to a 'global village' of tclecommunications and a 'spaceship carth' of economic and ecological interdependencies - to use just two familiar and everyday images - and as time horizons shorten to the point where the present is all there is (the world of the schizophrenic), so we have to learn how to cope with an overwhelming sense of compression of our spatial and temporal worlds. ...

The experience of time-space compression is challenging, exciling, stressful, and sometimes deeply troubling, capable of sparking, therefore, a diversity of social, cultural, and political responses (Harvcy, 1990:240).

Wenders's Wings of Desire is obviously one such creative response to "time-space compression". Baudrillard's cultural critique is another. Both enable one to understand and come to terms with a socio-cultural condition that affects us all. Moreover, the film and the critique in question reflect upon each other reciprocally, with mutual enrichment and clarification.

\subsection{Baudrillard's views on communication}

This article concentrates mainly on two of Baudrillard's essays - "The Implosion of Meaning in the Media "(in Baudrillard, 1983) and "The Ecstasy of Communication" (1985), which are particularly suitable for the line of argumentation. In both these essays, Baudrillard delineates the transformation that communication has undergone in advanced capitalist society. In an earlier essay, in "In the Shadow of the Silent Majorities", (1983:3536), he had contended that the media function via what he calls "fascination" (i.e., in McLuhan's terms, the neutralization of the message in favour of the medium), in this way undermining communication 'by meaning' in favour of another communicational mode. He now shows (1983:95-109) that the increase in this alternative mode, namely information, is matched by a correlative decrease in meaning. In his own words (1983:96):

... information is directly destructive of meaning and signification, or neutralizes it. The loss of meaning is directly linked to the dissolving and dissuasive action of information, the media, and the mass media.

This state of affairs is exactly the opposite of common belief, which holds that information 'creates' communication, as it were - in other words, that the two processes are essentially one and the same. However, instead of promoting communication - which, as has been pointed out earlier, presupposes an element of otherness, or a self-transcending reality information destroys its own contents. In order to explain why this happens, Baudrillard invokes his well-known thesis, that the real has been abolished by an all-encompassing process of simulation in advanced capitalist society. 


\subsection{Living in a simulated world}

According to Baudrillard the process of simulation means that, in this kind of society (which, with the exception of 'third world' areas, has virtually become global), we live in a totally simulated world, where the images, symbols, signs and concepts which are ordinarily regarded as mediating reality, have become self-sufficient. In other words, they no longer 'refer' to an object or a world, but comprise a 'hyperreality' of simulation in which we are trapped as in a closed, endlessly self-referential, self-simulating or self-replicating (Blade Runner!), circular process. Nietzsche's 'prison-house of language' has become a prisonhouse of 'simulacra'. That which people still mistakenly regard as 'real' is manufactured from memory banks, command models and miniaturized units - it is no more than operational (cf. Gillies, 1991:51). Although it is not of direct relevance here, it is interesting to note that this information-permeated, simulated hyperreality, by destroying the otherness, negativity and 'ontological difference' prerequisite for communication, also undermines the difference between the real and the imaginary as well as between true and false (Gillies, 1991:51), thus effectively invalidating science and critical thought. In Baudrillard's words (1983:35):

Critical thought judges and chooses, it produces differences, it is by selection that it presides over meaning. The masses [the pscudo-social counterpart of the process of simulation; B.O.], on the other hand, do not choose, they do not produce differences but a lack of differentiation - they retain a fascination for the medium which they prefer to the critical exigencies of the message.

If his assessment is correct, it means that the shadows on Plato's cave-wall have asserted themselves pervasively in this modern, so-called enlightened era. The formula, that culture, art, science or language mediates reality, then collapses in the face of a new, unforeseen immediacy in the sense that there is nothing to be mediated; that 'media' is in fact a misnomer because they fabricate (hyper-)reality, and that even the mediation of or by the media is a pseudo-mediation because the terms of the so-called mediation are determined by the media themselves. Hence, total circularity.

The way in which Baudrillard develops this vision in the later essay (1985) should highlight its relevance vis-à-vis Wings of Desire. Here the transformation of communication is traced in the 'proteinic' structure of networks, feedback and 'generalized interface', where both public and private space progressively disappear. The former is invaded and finally assimilated by advertising in its new version, which no longer simply promotes the sales of commodities, but becomes the all-pervasive organizing principle, through "omnipresent visibility" of public life and what used to be public scenery (Baudrillard, 1985:129). It is especially in his analysis of the loss of private space, which occurs simultaneously with the loss of public space, that the focal terrain of this paper is mapped out.

\subsection{The loss of private space}

While public space has lost its character of spectacle, resembling a great depthless screen instead, private space has lost its intimacy - it is 'no longer a secret'. This implies further that the opposition between exterior space as the 'scene of objects', and interiority as the sovereign space of the subject has been obliterated, resulting in what Baudrillard 
... a sort of obscenity where the most intimate processes of our life become the virtual fecding ground of the media ... Inversely, the entire universe comes to unfold arbitrarily on your domestic screen .... all this explodes the scene formerly preserved by the minimal separation of public and private ...

It is not difficult to understand what he is writing about here. Whether it is the formerly private, hidden details of some peasant or tribal communal or family ritual, or the rockface of some distant, challenging mountain; from the image-charting of global and planetary geography to the media-recording of the most intimate interhuman transactions everything has been brought within reach of the 'informed' (but unformed) masses in electronically reduced format. Baudrillard drives home the communicational consequences of this cultural condition in the following passage, which must be quoted in full, given its pertinence for the present theme. Referring to the lost era of the difference between public and private space, he writes (1985:130-131):

\begin{abstract}
Certainly, this private universe was alienating to the extent that it separated you from others - or from the world, where it was invested as a protective enclosure, an imaginary protector, a defence system. But it also reaped the symbolic benclits of alienation, which is that the Other cxists, and that otherness can fool you for the better or the worse. Thus consumer society lived also under the sign of alienation, as a socicty of the spectacle. But just so: as long as there is alienation, there is spectacle, action, seene. It is not obscenity - the spectacle is never obscene. Obscenity begins precisely when there is no more spectacle, no more scene, when all becomes transparence and immediate visibility, when everything is exposed to the harsh and incxorable light of information and communication.
\end{abstract}

\begin{abstract}
We are no longer a part of the drama of alienation; we live in the ecstasy of communication. And this ecstacy is obscene. The obscene is what does away with every mirror, every look, every image. The obscene puts an end to every representation. But it is not only the sexual that becomes obscene in pornography; today there is a whole pornography of information and communication, that is to say, of circuits and networks, a pornography of all functions and objects in their readability, their nuidity, their availabity, their regulation, in their forced signification, in their performativity, in their branching, in their polyvalence, in their free expression ... It is no longer then the traditional obscenity of what is hidden, repressed, forbidden or obscure; on the contrary, it is the obscenity of the visible, of the all-too-visible, of the more-visible-than-the-visible. It is the obscenity of what no longer has any secret, of what dissolves completely in information and communication.
\end{abstract}

\title{
4. Communication and history in Wings of Desire
}

It is not difficult to grasp the angelic vision-cum-hearing of Damiel and his fellow angels in Wings of Desire as the imaginative paradigm of this pervasive dimension of informationcommunication which abolishes all privacy and intimacy, all otherness and difference - in this way undercutting the a priori of communication in the normative sense, namely, that the reciprocity of communication presupposes otherness. The humanizing upshot of Damiel's desire to exchange the obscene omni-visibility and ubiquitous information of the angelic universe for the limitations of the self-and-other-structured perspectivism of human existence, is this: the degree to which the information-networks project a hyperreality of simulated worlds which ultimately exterminate the interstitial spaces that preserve human privacy and protect the reciprocity of communicative interaction, correlates with the extent to which the potential for interpersonal communication is eroded and distorted.

The point is - as Baudrillard enables one to see - the readily available information-systems create the illusion that everyone who is exposed to them is more informed, and hence better able to communicate, than the members of all previous generations. The truth, however, is that, in the place of the alienation that Baudrillard associates with the 
(obsolete) oppositional coexistence of a public and a private sphere, a new kind of alienation has appeared. Unlike the older alienation, which justifies and motivates communication - even if, as in the modernists' work, it is accompanied by epistemological despair - this postmodern alienation of a fragmented, ephemeral culture does not cultivate or vindicate communication precisely because it goes hand in hand with the belief in its own superiority as the realization of true communication. The angels in Wings of Desire often come across as weary - they are seen resting in the library, for instance - which makes sense given the unbearable lightness of their being, i.e. the indescribable boredom of the instantaneous informational mode to which they are privy. The following remark by Harvey therefore comes as no surprise (1990:320-321):

The fact that many angels, according to Falk [in the film; B.O.], have chosen to come to earth, suggests that it is better always to be inside than outside the flow of human time, that becoming always has the potential to break with the stasis of being.

After all, one can only desire that which is other, which is not entirely within your reach or obscenely available; implying, not that this is why Damiel desires Marion, but why he desires human desire - the condition of the possibility of experiencing anything as opaque and anyone as other, as desirable.

\subsection{A descriptive and a normative sense of communication}

We have to distinguish, therefore, between two senses of communication - a descriptive and a normative sense, respectively. Baudrillard uses it in the normative sense in the earlier essay (1983:97-98) where he talks about information 'devouring' communication. In the later essay (1985), however, he seems to equate the two, implicitly suggesting that in postmodern culture the process is complete: information has finally assimilated communication; descriptively speaking, communication in the informational mode is all that is left. This explains Wenders's attempt to resurrect a sense of the normative mode in the process of communication that develops between Damiel and Marion. Two things are important here. Firstly, one should question Baudrillard's cultural critique, especially with regard to its totalizing character.

Is it not the case that, within the hyperreality of postmodern, advanced capitalist society, there are still areas or, more modestly, pockets of genuine communication, where actual interpersonal practices approximate the communicational norm - even if full, reciprocal 'presence' is never actualized? (If it were, it would destroy the a priori of communication, viz. the preservation of otherness, anyway.) Communication in this 'minimal' sense is still a possibility and often an actuality, and I therefore agree with Harvey $(1990: 291,300,351)$ that Baudrillard - while drawing our attention to important cultural transformations exaggerates somewhat. Gillies (1991:61), too, criticizes Baudrillard while admitting the provocativeness of his vision. For him, Baudrillard's contention that the real, the object, has disappeared, entails the concomitant abolition of history and the future, which further implies that, in (neo-) Marxist terms, there is no possibility of redemption. After all, as Adorno knew, there is hope only if what is, is not all that can be.

\subsection{Does viable communication presuppose an historical context?}

The question of history is important here because it resurrects the earlier allusion to the 
function of the intermittently appearing old man in Wings of Desire while, at the same time, addressing the other remaining issue of the adequacy of the combined story or narrative initiated by Damiel and Marion. Simply put: is a sense of common purpose, born of romantic love, enough to serve as a paradigm for a culture awash in the socio-economic effects of time-space compression? As Harvey (1990:321) reminds us, Damiel has no history. (It is striking that, in this respect as well, the timeless angel exemplifies an aspect of postmodernity, viz. its loss of temporal or historical continuity, or what Jameson [1985:119] metaphorically terms its schizophrenia.) Add to this the fact that, when they meet, Marion is rootless as well, and the problem assumes frightening proportions. Harvey puts it tersely (1990:321): "Is it possible to set about the project of becoming a-historically ?" He then proceeds by arguing that the old storyteller seems to question the viability of such an undertaking. The fact that the storyteller - who understands himself to be the "potential guardian of collective memory and history" (Harvey, 1990:317) - is an old person, who would have been young before ephemerality and fragmentation became pervasive structural features of contemporary culture, makes him the embodiment of memory, a structural property sadly lacking in this culture.

His role is ambiguous because he is a peripheral figure by his own admission: the group of listeners who used to gather around him has dispersed, having become mutually uncommunicative readers. (Ironically, he frequents the library in an attempt to preserve a sense of the history of Berlin!) The impression of societal fragmentation that pervades the film is reinforced when the old man complains that even language seems to dissolve into incoherent fragments. On the other hand, however - and this is where he interrogates the prospects of the project inaugurated by Marion and her ex-angel man - he insists that he cannot give up his narrative task, because without its storyteller mankind would lose its childhood. It would seem, then, that the old man embodies a corrective to the apparently a-historical project represented by Marion and Damiel. Is Wenders telling us that viable communication presupposes a narrative or historical context? If this is the case, it would be in agreement with this line of thought in the work of Gadamer, Habermas and MacIntyre, all of whom insist on an indispensable historical moment in interhuman communication.

In this way, finally, a problem is posed for postmodernity: given the fact that it lacks a sense of history or continuity - already implied and aggravated by what many critics see as the preponderance of (an aestheticized) spatial sensibility - what critical potential exists, and where, for a project of communication which would or could recuperate a sense of common purpose without totalizing effects?

To put it in the language of Wings of Desire: how does an angelic culture (or one which aspires to angelicism, anyway (think of the implications of the 'quest for zero defect') make its (re-)entry into human time and history? The dilemma that faces Marion and Damiel epitomizes the dilemma facing postmodern culture.

\section{A digression: more postmodern cinema}

To be sure, some theorists embrace the a-historicality and schizophrenia prevalent in contemporary Western culture (cf. Harvey, 1990:351), attempting to 'ride the tiger' of timespace compression. Others - such as Ridley Scott and Woody Allen - while providing striking cinematic images of ephemerality and replication, address this state of affairs in 
different ways. In Blade Runner, (cf. Harvey, 1990:312) Scott has the replicants destroy their maker in a classic rebellion of simulacra granted a limited lifespan, again involving a clash of time scales - this time between humans and their replicas who, like Damiel, have no history either. Ironically, in Blade Runner the central character, Deckard, escapes from a decaying, post-industrial Los Angeles with a new-generation replicant, Rachel, who has no built-in limited lifespan, in a bid for happiness. This, however, is not really a satisfactory resolution, despite the reversion to time - by changing Rachel's lifespan - in an attempt to reach one, and a politically sterile one into the bargain. Despite obvious similarities with Wings of Desire, Blade Runner fails to address the problem of communication as seriously as the German film does. Both seem ambivalent with regard to the dilemma issuing from the absence of an historical context for the non-human agents, and in a certain sense for the humans as well.

Woody Allen's Zelig, on the other hand, while presenting the audience with a chameleonlike subject that changes constantly by replicating the other in his immediate vicinity, retains a critical-parodic edge because it "... works both to underline and to undermine the notion of the coherent, self-sufficient subject as the source of meaning or action", in Linda Hutcheon's words (1989:109). The unstable character Zelig mimics its own culture, while it parodies the idealized modernist subject with its projected unity, integrity and wholeness, in this way questioning the historical construction of subjectivity and the public media's function in that process, insofar as the latter is responsible for the pseudo-unity of the endlessly mutating human cipher. Allen achieves a notable effect here, by destroying otherness through a character who incessantly replicates others, ultimately leaving his audience with the thought-provoking question concerning the requirements for a subject of historical significance.

This little excursion on two other examples of postmodern cinema emphasizes the fact that these films, while imitating the structure of their material cultural context, do not do so passively, but engage critically with the problems that confront this culture. The discussion of Wings of Desire further illustrates that, while a film may reconstruct postmodern culture and its attendant contradictions - Baudrillard would say repetitions, which is contradictory in historical terms, anyway - very effectively, its treatment of these may in fact amount to a modernist project for the solution of a postmodern problem. Nor should this surprise us, for, as Lyotard observes perspicaciously (1984:79): "A work can become modern only if it is first postmodern. Postmodernism thus understood is not modernism at its end but in the nascent state, and this state is constant." Seen in this way, modernism is the movement which counters the endless instability of the postmodern moment with stable forms. In these terms, Wings of Desire exemplifies the conjunction of these two distinguishable, but inseparable cultural modes.

\section{Concluding remarks: what about South Africa?}

Some readers may wonder what relevance the present interpretation of Wings of Desire in terms of modernism and postmodernism could possibly have for the South African cultural, socio-economic and political situation. Is this analysis not applicable exclusively to advanced capitalist countries such as (West-)Germany, France, Britain and the United States? South Africa seems to have cultural hybrid-status compared to these countries. I would therefore argue that, although social life in certain metropolitan areas in South Africa displays the same structural features, labelled 'postmodern' - fragmentation and 
ephemerality - in this essay, it is only partly for the same reason as in advanced capitalist societies, namely because of the 'time-space compression'-effect of the process of (capitalist) modernization. One might say, not inaccurately, I believe, that the condition of cultural fragmentation in this country (S.A.) has post- and pre-modern features. More specifically, it is the result of an initial confrontation between a colonized (indigenous) culture and a colonizing (alien) culture in which the latter's dominance and domination over the former, seriously affected its historical and narrative continuity as well as its social (including educational and moral) coherence. This state of affairs continued in postcolonial times and was aggravated to the point of social pathology by coercive structural practices of exclusion (in Foucauldian terms) during the apartheid-epoch. In other words, South African society is a fragmented society for the additional reason (in metropolitan areas, and for the predominant reason, in rural areas) of the ideologically motivated, socially and politically divisive effect of apartheid practices in law, industry, education, religion, and so on. With this in mind, it should be (terrifyingly) clear that South Africans are faced with the awesome project of overcoming the legacy of a pathologically divided history and creating the basis for a united, communicatively interactive 'future history', to put it oxymoronically.

This does not, as some may think, require historical amnesia with regard to the time of apartheid. Kundera (and before him Adorno) has warned about the dangers of forgetting. It requires, precisely, remembering (not commemorating or celebrating) the effects of apartheid and expiation for apartheid, lest it become an empty name of no axiological significance for future generations. Only in this way is interpersonal reconciliation possible. And, as for postmodern culture, this requires communication despite (and motivated by) remaining barriers. Needless to say, a crucial contribution to such a South African communicative project could and should come from educational institutions primary through secondary to tertiary ones. These institutions (especially universities) have the linguistic, intellectual, scientific - in a word, the rational - resources to initiate and sustain the project of conciliatory, re-integrative communication in South Africa.

\section{Bibliography}

Baudrillard, J. 1985. The Ecstasy of Communication. In: Foster, H. The Anti-Aesthetic: Essays on Postmodem Culture. Port Townsend : Bay Press. p. 126-134.

Baudrillard, J. 1983. In the Shadow of the Silent Majorities ... or the End of the Social, and Other Essays. Tr. Foss, P., Patton, P. and Johnston, J. New York : Scmiotext(c), Inc.

Gillies, F. 1991. Hoping without Reason, Image or Object, or: How to Get from Marx to Baudrillard. In: The Provocation of Balıdrillard. Ed. Ackbass. Hong Kong : Hong Kong University Press. p. 4967.

Harvey, D. 1990. The Condition of Postmodentity. Oxford : Basil Blackwcll.

Hutcheon, L. 1989. The Politics of Postmodemism. London : Routledge.

Jameson, F. 1985. Postmodernism and Consumer Socicty. In: Foster, H.: The Anti-Aesthetic: Essays on Postmodem Culturc. Port Townsend, Washington : Bay Press. p. 111-125.

Lyotard, J-F. 1984. The Postmodern Condition: A Report on Knowledge. Tr. Massumi, B. and Bennington, G. Manchester : Manchester University Press.

Nicholls, P. 1991. Divergences; Modernism, Postmodernism, Jameson and Lyotard. Critical Quarterly, 33(3). Autumn, p. 1-18.

University of Port Elizabeth 